\title{
Visitando a Interação na Prosa Literária
}

\author{
(Visiting the Interaction in the Literary Prose)
}

\author{
Dóris de Arruda C. da CunHA \\ (UFPE/CNPq)
}

\begin{abstract}
O enunciado concreto (e não a abstração lingüística) nasce, vive e morre no processo da interação social entre os participantes da enunciação. Sua forma e significado são determinados basicamente pela forma e caráter desta interação. (Bakhtin, 1976:9).
\end{abstract}

ABSTRACT: The aim of this paper is to analyse the interaction in the novel, starting from the principle that discourses can not be structured as reported speeches, for they are representations of the interaction between subjects and their axiological positions. This paper also analyses the relationship between Linguistics and Literature, sharing Maingueneau's view that one can not continue to think this relationship dichotomically, for both sciences of language bring new discoveries for the literary text. Taking Bakbtinian discourse theory as our base, this article studies the discourses in a fragment of Capitães de Areia, which reveals the clash of views of the world: that of the elite and that of the excluded, represented artistically in the novel.

KEYS-WORDS: interaction; novel; discourse; social voices.

Resumo: Este artigo tem o objetivo analisar a interação por meio dos discursos no romance, partindo do princípio que não são formas sintáticas de transmissão das falas e dos pensamentos das personagens, mas representações da interação entre sujeitos e suas posições axiológicas. Analisa a relação entre Lingüística e Literatura, partilbando a visão de Maingueneau segundo a qual não se pode continuar a pensar dicotomicamente essa relação, uma vez que as duas ciências da linguagem trazem novas descobertas para o texto literário. Tomando por base a teoria bakbtiniana, faz um estudo dos discursos num fragmento de Capitães da Areia, que revela o embate de visões de mundo, a das elites e a dos excluídos, representados artisticamente nesse romance.

PALAVRAS-CHAVE: interação; romance; discurso; vozes sociais. 


\section{Introdução}

Gostaríamos de iniciar explicando algumas orientações que justificam os limites da abordagem aqui apresentada. Este artigo dá continuidade a pesquisas anteriores no âmbito das enunciações na, sobre e dentro da enunciação. A multiplicidade de procedimentos para abordá-la é enorme, sendo necessário colocar as questões sobre a diversidade de planos enunciativos numa ordem: das marcas formais aos indícios verbais e/ou situacionais, alguns meios são partilhados, os níveis de impacto se escalonam, os efeitos de sentido se desenham.

Em estudos anteriores, abordamos a enunciação com diferentes procedimentos e de diferentes ângulos. Inicialmente, o objeto de estudo foi o discurso reportado não do ponto de vista da língua, como se fazia tradicionalmente, descrevendo-se os mecanismos morfossintáticos das formas de transmissão de um discurso no nível da frase ou do enunciado, a partir de textos escritos. Partindo dos postulados bakhtinianos, optamos por uma abordagem dialógica do discurso de outrem, considerando o contexto e a situação enunciativa, a tensão, a dinâmica e a inter-relação que ligam as formas com o contexto narrativo no qual elas aparecem, a qualidade da relação entre o enunciador que cita e o locutor da enunciação anterior, e entre o primeiro e a terceira pessoa para a qual a enunciação reportada é dirigida. O resultado (Cunha, 1992) confirmou as hipóteses iniciais de que há um contínuo que vai das formas canônicas de citação às retomadas não marcadas do discurso retomado e modificado. O deslocamento das formas da língua para a enunciação mostrou que o discurso citado, até então considerado um "problema restrito", é um fenômeno central no funcionamento da linguagem. O estudo empírico do corpus oral levou a um importante avanço teórico, na medida em que pudemos verificar que o discurso reportado só pode ser compreendido no âmbito da interação verbal tomada como um todo. Nessa perspectiva dialógica, foram desvelados os processos significantes da circulação discursiva: o que vários sujeitos fazem com o discurso de outrem, o que acentua, o que desloca, o que acrescenta, o que suprime, em função da posição do locutor em relação ao objeto do discurso e ao interlocutor; e a diversidade de modos de relação ao discurso de outrem que depende, entre outros, dos conhecimentos partilhados pelos interlocutores (Cunha, 1992, 1995). 
Prosseguimos estas pesquisas sobre a retomada do discurso nas duas modalidades da língua - a fala e a escrita - procurando, com base na teoria de Bakhtin, elementos no âmbito da enunciação para explicar as relações entre estas modalidades (Cunha, 1997, 1998). O exame de um corpus constituído de conversações, notícias, editoriais, reportagens, artigos científicos, conferências, palestras, aulas, cartas revelou que o lugar dado ao discurso de outrem - mostrado ou marcado como tal - constitui um índice pertinente de diferenças entre gêneros (Cunha, 2002, 2003, 2004) e não entre duas modalidades da língua.

Foi nesse percurso, do dialogismo marcado ao constitutivo ${ }^{1}$, buscando por meio das formas de representação de um dizer outro compreender posições enunciativas, relação entre os interlocutores, o papel dos sujeitos que inscrevem o outro em seus textos que estudamos o discurso literário ${ }^{2}$ (Cunha, 2003; 2004), lugar privilegiado para a observação da pluralidade de linguagens, de gêneros, de estilos, de vozes marcadas ou mostradas, que revelam ao lingüista as redes dialógicas constitutivas da linguagem. Examinamos também, a partir de um corpus constituído de contos e romances brasileiros, a passagem, no período de um século, do visível - vozes marcadas tipograficamente - ao audivel - vozes mostradas e não marcadas (Cunha e Valois, 2003).

O discurso reportado, como se vê, é um tema articulador das reflexões lingüísticas e literárias, levando pesquisadores das duas áreas a revisitar escritores clássicos e contemporâneos da literatura (La Fontaine, Proust, Machado de Assis, Rubem Fonseca, etc.) e a defender posições teóricas em função dos gêneros observados.

\section{Interação entre duas ciências da linguagem}

Um estudo sobre a interação nos gêneros literários em prosa enquanto lingüista decorre também de uma concepção da relação entre a Lingüística

1. Do dialogismo marcado ao constitutivo - um estudo da representação do discurso outro, título de um projeto de pesquisa aprovado pelo CNPq para o biênio 2003-2005

2. Fizemos um caminho inverso, do "discurso na vida" para "o discurso na arte", uma vez que a maioria dos estudos consagrados ao discurso reportado voltou-se para os gêneros literários, posteriormente, para os da imprensa e só nos vinte anos é que o discurso reportado em gêneros orais foi objeto de estudo. 
e a Teoria da Literatura ainda não partilhada amplamente pelos lingüistas e teóricos da literatura, ou seja, a de que as duas ciências da linguagem trazem novas descobertas para o texto literário. Partilhamos com Maingueneau $(2000,2004)$ a visão de que não se pode continuar a pensar dicotomicamente essa relação, com base numa visão de discurso que remonta ao século XIX: o literário era considerado intransitivo, autotélico, "exceção a tudo” (Mallarmé, apud Maingueneau, 2002); e o não literário, transitivo, a serviço de finalidades exteriores. Para Maingueneau (2000, 2004), a Análise do Discurso, tomando como objeto de estudo todo e qualquer gênero, recoloca o discurso literário na multiplicidade das enunciações que atravessam o espaço social.

Relembremos rapidamente com Maingueneau como se deram as relações entre Lingüística e Literatura. Até os anos 1960, a Gramática Histórica foi o instrumento teórico quando se tratava de "definir" o texto literário do ponto de vista filológico. A Estilística foi o lócus onde a relação entre Lingüística e Literatura foi mais estreita. A Estilística Lingüística (também chamada de escolar ou tradicional) dedicava-se ao estudo dos tropos e dos procedimentos expressivos usados pelo autor para criar certo efeito sobre o leitor, como as exclamações, anteposição do adjetivo e análises fonológicas, morfossintáticas com base nos termos usuais da gramática tradicional. A Estilística Literária, ligada ao romantismo, que se propunha a "descobrir" a consciência do autor, expressa na obra, manteve relações ambíguas com a Lingüística, uma vez que poucas categorias de análise eram usadas, a exemplo do uso do imperfeito. A Lingüística não era, portanto, etapa obrigatória para se chegar à consciência do autor.

A partir dos anos 1960, com o apogeu do estruturalismo, os teóricos consideravam que a Lingüística Estrutural seria o meio para elaborar uma Ciência Literária, substituindo o arsenal de noções gramaticais e conferindo à primeira um papel heurístico. As noções de sintagma, paradigma, conotação, significante, actante, entre outras, foram incorporadas à Literatura. A Poética, que prolongou os estudos dos Formalistas Russos, desenvolveu-se bastante a partir do Círculo Lingüístico de Praga e um dos seus postulados fundamentais, a função poética, é baseado na análise de certas propriedades das línguas naturais, especialmente no nível fonológico. $\mathrm{O}$ estudo do vocabulário das obras literárias também foi desenvolvido, por ser a Lingüística Estrutural a Ciência do Signo e pelas possibilidades que esse nível de estudo oferece à interpretação dos textos. 
Nos anos 60 e 70, enquanto a Lingüística Estrutural se estabilizava no estudo das estruturas lingüísticas, o distanciamento entre as duas ciências da linguagem foi gradativamente se ampliando. Só com o surgimento das tendências enunciativa, discursiva, textual e pragmática é que alguns conceitos ligados ao estudo do discurso e do texto passam a ser operatórios para os gêneros literários: situação e cena de enunciação, dêiticos, focalização e pontos de vista, heterogeneidade enunciativa, discurso reportado, gênero, posicionamento, etc.

Entretanto, para utilizá-los, é necessário considerar, ainda segundo Maingueneau (2004:30), dois pontos que vão de encontro aos postulados dos estudiosos da literatura:

1. a literatura não se beneficia de um terreno de extraterritorialidade. Dessa forma, a Análise do Discurso não pode se dedicar apenas aos textos não literários, considerados transitivos ou profanos, em oposição aos literários, intransitivos ou sagrados, na linha da estética romântica. A Análise do Discurso explora as múltiplas dimensões da discursividade e busca definir o quadro no interior do qual se desenham as múltiplas "leituras" que uma obra autoriza;

2. a distribuição dos papéis entre a Lingüística e a Estilística, que teve origem no século passado: não se trata mais de recorrer à Lingüística para obter instrumentos básicos para análise dos textos literários, mas para constituir protocolos de pesquisa e interpretações.

Para Maingueneau (2000), o centro não é mais o autor nem o contexto de sua criação, nem o texto, mas o dispositivo de comunicação,

"onde as condições do dizer atravessam o dito e onde o dito remete às suas próprias condições de enunciação (o status do escritor associado ao seu modo de posicionamento no campo literário, os papéis ligados aos gêneros, a relação com o destinatário, construída através da obra, os suportes materiais e os modos de circulação dos enunciados...)" Maingueneau (2000).

Precedendo de quase um século a posição de Maingueneau sobre o discurso literário, Bakhtin analisou nos anos vinte o discurso em Dostoiévski e propôs uma disciplina, a Metalingüística, para estudar os aspectos da vida do discurso, especialmente o discurso bivocal que surge no âmbito da comunicação dialógica. Como lembra Brait (2006:26) "o pensamento 
bakhtiniano, para falar da linguagem em uso e avançar em sua concepção social e histórica de linguagem, não descarta qualquer tipo de discurso".

Embora Maingueneau apresente de forma didática a história da relação das duas disciplinas, é com base na teoria dialógica do pensador russo que analisamos a interação no gênero romanesco, pois consideramos com Brait (2006:9) que "o pensamento bakhtiniano representa, hoje, uma das maiores contribuições para os estudos da linguagem, observada tanto em suas manifestações artísticas como na diversidade de sua riqueza cotidiana”.

\section{A interação em Bakhtin}

Nos últimos 30 anos, diversas teorias tomaram a interação e a linguagem na interação como objeto de estudo, considerando interação uma noção adquirida e consensual. Entretanto, esse consenso não corresponde à realidade da pesquisa.

Vale lembrar que antes de ser objeto de análise científica a interação foi tema da reflexão filosófica desde o século XVIII, motivada pela concepção de sujeito como individual e senhor do próprio conhecimento, como lembra Faraco (2005a). Nesse trabalho ${ }^{3}$, o lingüista apresenta uma excelente revisão cronológica e temática de alguns dos principais percursos científicos e filosóficos que têm o foco sobre a interação e a linguagem na interação ${ }^{4}$.

3. Conferência de encerramento do Congresso Internacional Linguagem e Interaşãa, realizado na UNISINOS (São Leopoldo - RS), 2005.

4. Faraco aponta o percurso de alguns filósofos que pensaram o homem numa perspectiva dialógica: Jacobi (apud Faraco, 2005: "Eu é impossível sem o Tu"); Hegel (apud Faraco, 2005: "A consciência-de-si é em-si e para-si enquanto e porque é em-si e para-si para outra consciência-de-si; ou seja, ela só é na medida em que é um ser reconhecido"); Feuerbach (apud Faraco, 2005: "Certamente que o idealismo sabe (...) que sem tu não há eu, mas este ponto de vista no qual há um eu e um tu, é para ele apenas o empírico, não o transcendental, quer dizer, verdadeiro, não é o primeiro e originário, mas um ponto de vista subordinado, que é válido para a vida, mas não para a especulação"). Buber (apud Faraco, 2005: "Me torno na relação com o Tu). A reflexão filosófica não só responde a um pensamento da época de um indivíduo tomado como elemento axiomático mas também à preocupação com a dimensão ética que perpassa a interação. Ainda segundo Faraco, Lévinas (1906-1995) criticava qualquer abordagem apenas intelectualista da interação. Para ele, (apud Faraco, 2005). "a interação é desde sempre uma relação que nos obriga a responder à face (à exterioridade do outro): antes e para além de ser objetificada, a interrelação é, portanto, vivida." 
Na perspectiva filosófica bakhtiniana, a interação está ligada à vida, à alteridade e à ética. Viver é interagir: "ser significa ser para um outro, e por meio do outro, ser para si mesmo". Bakhtin postula uma concepção de ser em que o outro é parte constitutiva, ou seja, em que o homem não existe fora da relação com o outro, que se dá por meio da linguagem, constitutivamente dialógica:

"é verdade que até na vida procedemos assim a torto e a direito, avaliamos a nós mesmos do ponto de vista dos outros, através do outro procuramos compreender e levar em conta os momentos transgredientes a nossa própria consciência: /... em suma, espreitamos tensa e permanentemente, captamos os reflexos da nossa vida no plano da consciência dos outros /.../." (Bakhtin, 2003).

Para Bakhtin (1997:180), o homem nunca encontrará sua plenitude apenas em si mesmo, sendo por meio da troca linguageira que começa a vida: a criança recebe da boca da mãe e dos próximos num processo contínuo e ininterrupto de interação tudo que a determina inicialmente, ela e seu próprio corpo:

"dos lábios dela, no tom volitivo-emocional do seu amor, a criança ouve e começa a reconhecer o seu nome, a denominação de todos os elementos relacionados ao seu corpo e às vivências e estados anteriores; são palavras de pessoas que ama as primeiras palavras sobre ela, as mais autorizadas que pela primeira vez lhe determinam de fora a personalidade e vão ao encontro da sua própria e obscura auto-sensação interior, dando-lhe forma e nome em que pela primeira vez ela toma consciência de si e se localiza como algo" (Bakhtin, 2003:46).

É importante destacar que é o amor do outro na interação dialógica que dá direito à existência. Dialogismo significando, na leitura de François (2006), presença do outro em nós, embora não saibamos bem como dar uma figura teórica do modo de ser do outro em nós. Na realidade, Bakhtin aponta diferentes dimensões do fenômeno. $\mathrm{O}$ conceito remete à presença do outro em todas as produções verbais, antecipando as possíveis objeções e questionamentos, às relação com o já-dito e o por vir, à condição humana, à heterogeneidade fundamental do sujeito e das formas de sentido. Nessa perspectiva, o pensamento e a idéia começam a ter vida quando contraem relações dialógicas essenciais com os discursos e as idéias dos outros: 
"A idéia não vive na consciência individual isolada de um homem: mantendo-se apenas nessa consciência, ela degenera e morre. Somente quando contrai relações dialógicas essenciais com as idéias dos outros é que a idéia começa a ter vida, isto é, a formar-se, desenvolver-se, a encontrar e renovar sua expressão verbal, a gerar novas idéias". (Bakhtin, 1997:86-87).

Como o sujeito, o pensamento, a idéia e consciência, a experiência discursiva do ser só se concretiza e se desenvolve no movimento contínuo de interação. Por isso, a aquisição da linguagem não pode ser pensada em termos de formas da língua, mas de assimilação dos discursos do outro:

" $[\ldots .$.$] a experiência discursiva individual de qualquer pessoa se forma e se desenvolve$ em uma interaçã $0^{5}$ constante e contínua com os enunciados individuais dos outros. Em certo sentido, essa experiência pode ser caracterizada como processo de assimilação - mais ou menos criador - das palavras do outro (e não das palavras da língua). Nosso discurso, isto é, todos os nossos enunciados (inclusive as obras criadas) é pleno de palavras dos outros, de um grau vário de alteridade ou de assimilabilidade, de um certo grau vário de aperceptibilidade e de relevância. Essas palavras dos outros trazem consigo a sua expressão, o seu tom valorativo que assimilamos, reelaboramos e reacentuamos." (Bakhtin, 2003:295)

Não há palavra que seja primeira ou última nem limite para o contexto dialógico, que se perde num passado e num futuro ilimitados, como reflete François (2006). Em Problemas da Poética de Dostoievski, Bakhtin volta-se para o discurso, constituído nas relações dialógicas, lugar onde a língua converte-se em posições de sujeitos e ganha autor, criador do enunciado. $\mathrm{O}$ discurso pertence ao campo da Metalingüística bem como "os tipos e graus de alteridade da palavra alheia e as diferentes formas de relação com ela (estilização, paródia, polêmica, etc.), dos diversos meios da sua exclusão da vida do discurso" (Bakhtin, 2003:368). A proposta de Bakhtin é ir além de uma análise dos fatos da língua e tomar como objeto a natureza dialógica do homem por meio da linguagem.

Decorre dessa visão, a elaboração de um estudo da interação entre os discursos, que constitui uma "revolução teórica" (François, 2006). Na terceira parte do Marxismo e filosofia da linguagem, Bakhtin e Voloshinov (1995) colocam o discurso de outrem, a interação, o contraste e a mistura de vozes, de visões de mundo e de perspectivas de uma mesma realidade, no

5. Grifo nosso. 
centro dos estudos da linguagem e do diálogo. No diálogo de duas enunciações, de dois sujeitos enunciando, constroem-se índices, indícios que referem ao status sócio-ideológico da linguagem. No Discurso no romance, Bakhtin mostra a amplitude do fenômeno, a onipresença do discurso de outrem na vida e na literatura, o diálogo incessante das forças sociais, dos tempos, das épocas.

"Um enunciado vivo, significativamente surgido em um momento histórico e em um meio social determinados, não pode deixar de se relacionar com os milhares de fios dialógicos vivos, tecidos pela consciência sócio-ideológica em torno do objeto de tal enunciado e de participar ativamente do diálogo social. De resto, é dele que o enunciado se origina: ele é como a sua continuação, sua réplica, ele não aborda o objeto chegando de não se sabe de onde." (Bakhtin, 1993:86).

A teoria dialógica da linguagem de Bakhtin levou a Lingüística a sair da dicotomia língua-fala, estabelecendo o enunciado como a unidade da comunicação verbal, realizada por meio de enunciados ou gêneros discursivos, que por sua vez são definidos por critérios enunciativos, ligados às condições sociais de produção. Nessa perspectiva, o gênero é constituído nas diferentes esferas da comunicação humana, por um locutor, que tem um propósito comunicativo, elaborado em função do alocutário: "a escolha (de um gênero) é determinada em função da especificidade da esfera em que ocorre a interação verbal, das necessidades de uma temática (do objeto de sentido) e do conjunto constituído pelos participantes, etc." (Bakhtin, 2003:284).

À luz do dialogismo bakhtiniano, o gênero é processo e produto da interação e dinamiza as relações entre interlocutores. E o romance é o gênero que representa artisticamente a interação entre vozes sociais. Fenômeno plurivocal, plurilingüístico e pluriestilístico é também o lugar em que a estratificação da linguagem se revela e revela o homem que fala, uma vez que todas as linguagens sociais são "pontos de vista específicos sobre o mundo, formas da sua interpretação verbal, perspectivas específicas, objetais, semânticas e axiológicas" (Bakhtin, 1993:98). A interação discursiva entre essas linguagens ou discursos pode ocorrer na forma de confronto, repúdio, complemento mútuo, solidariedade, correspondência. O texto do romance é, portanto, representação artística da interação humana.

Bakhtin (1993) considera o discurso no romance discurso de outrem, na língua de outrem, uma vez que o autor reporta discursos em interação 
- do narrador e das personagens, orquestrando vozes sociais. No entanto, identificar a voz do autor não é tarefa fácil: "por trás do relato do narrador, nós lemos um segundo, o relato do autor sobre o que narra o narrador, e, além disso, sobre o próprio narrador" (p. 118). Na teoria bakhtiniana do romance, há dois planos na narração: o do narrador e o do autor, que realiza sua intenção de modo refratado na narração e através dela. O mesmo ocorre com as falas das personagens: elas também podem refratar as intenções do autor, podendo ser a segunda linguagem do autor. Por outro lado, nessa interação dialógica, o discurso da personagem exerce influências sobre o do autor, misturando-se a ele com funções diversas - ironizar, estilizar, criticar, zombar.

Bakhtin analisa a mistura dos discursos do autor, narrador e personagem, no seio de um mesmo enunciado, identificáveis pelas mudanças de tom, pelo contraste entre a elevação da sintaxe e a vulgaridade do vocabulário, o tipo de interação. O que significa que a percepção das tonalidades, da ironia, das posições axiológicas depende da recepção.

Há ainda um outro tipo de interação no romance: a que se dá por meio dos gêneros intercalados, primários e secundários, os quais conservam sua autonomia, mas exercem um papel estrutural básico como as cartas, diários, biografia, notícias de jornal, etc. Segundo Bakhtin (1993:125), “o papel desses gêneros intercalados é tão grande que pode parecer que o romance esteja privado de sua primeira abordagem verbal da realidade e precise de uma elaboração preliminar desta realidade por intermédio de outros gêneros, ele mesmo sendo apenas uma unificação sincrética, em segundo grau, desses gêneros verbais primeiros". Eles aparecem "como narração que 'não parte do autor' (do narrador, do suposto autor, do personagem), mas refrangem as intenções dele (do autor)". (Bakhtin 1993:126).

Os exemplos a seguir mostrarão a interação por meio dos discursos, incluindo os gêneros intercalados que funcionam como discursos reportados (Cunha 2004), em Capitães da Areia, de Jorge Amado.

\section{A interação em Capitães da areia}

Capitães da Areia, de Jorge Amado, inicia-se com uma seção intitulada Cartas à redação. O leitor se defronta aí primeiramente com outro gênero 
cuja referência aparece entre parênteses no texto: Reportagem publicada no "JORNAL DA TARDE", na página de "Fatos policiais", com um clichê da casa do Comendador e um deste no momento em que era condecorado:

\section{CRIANÇAS LADRONAS}

AS AVENTURAS SINISTRAS DOS “CAPITÃES DA AREIA” - A CIDADE INFESTADA POR CRIANÇAS QUE VIVEM DO FURTO - URGE UMA PROVIDÊNCIA DO JUIZ DE MENORES E DO CHEFE DE POLÍCIA - ONTEM HOUVE MAIS UM ASSALTO

Já por várias vezes o nosso jornal, que é sem dúvida o órgão das mais legítimas aspirações da população baiana, tem trazido notícias sobre as atividades criminosas dos "Capitães da areia", nome pelo qual é conhecido o grupo de meninos assaltantes e ladrões que infestam a nossa urbe /.../

Esse bando que vive de rapina,_se compõe, pelo que se sabe, de um número superior a 100 crianças das mais diversas idades, indo desde os 8 aos 16 anos. Crianças que, naturalmente, devido ao desprezo dado à sua educação por pais pouco servidos de sentimentos cristãos, se entregaram no verdor dos anos a uma vida criminosa. /... E tem por comandante um molecote dos seus 14 anos, que é o mais terrível de todos, não só ladrão, como já autor de um crime de ferimentos graves, praticado na tarde de ontem. /.../

O que se faz necessário é uma urgente providência da Polícia e do Juizado de Menores no sentido da extinção desse bando e para que se recolbam esses precoces criminosos, que já não deixam a cidade dormir em paz o seu sono tão merecido, aos institutos de reforma de crianças ou às prisões ${ }^{6}$. (..) Passemos agora a relatar o assalto de ontem, do qual foi vítima um honrado comerciante da nossa praça [o Comendador], que teve sua residência furtada em mais de um conto de réis (...)

Nesses parágrafos iniciais de Capitães da Areia, o discurso de outrem, no artigo de jornal, é introduzido sem a voz do narrador. A linguagem desse gênero com suas vozes e linguagens sociais, seu vocabulário e pontos de vistas ferozmente hostis aos meninos de rua configura-se como uma estilização paródica do discurso das elites, da opinião corrente e da imprensa, a serviço dessas elites, refratando assim as intenções do autor de denúncia dessa posição axiológica e das conseqüentes formas de ação. A posição explicitamente defendida pela reportagem é desumana ("o grupo de meninos assaltantes e ladrões que infestam a nossa urbe"), cruel, violenta e perversa ("O que se faz necessário é uma urgente providência da Polícia e do Juizado de Menores no sentido da extinção desse bando e para que se recolham esses precoces criminosos").

6. Todos os grifos nos exemplos são nossos (em itálico). 
A reportagem é seguida por cinco cartas, às quais sucede o título de uma outra reportagem publicada depois das cartas:

CARTA DO SECRETÁRIO DO CHEFE DE POLÍCIA À REDAÇÃO DO “JORNAL DA TARDE"

CARTA DO DOUTOR JUIZ DE MENORES À REDAÇÃO DO "JORNAL DA TARDE"

CARTA DE UMA MÃE, COSTUREIRA, À REDAÇÃO DO "JORNAL DA TARDE" CARTA DO PADRE JOSÉ PEDRO À REDAÇÃO DO "JORNAL DA TARDE" CARTA DO DIRETOR DO REFORMATÓRIO À REDAÇÃO DO “JORNAL DA TARDE"

ESTABELECIMENTO MODELAR ONDE REINAM A PAZ E O TRABALHO UM DIRETOR QUE É UM AMIGO - ÓTIMA COMIDA - CRIANÇAS QUE TRABALHAM E SE DIVERTEM - CRIANÇAS LADRONAS EM CAMINHO DA REGENERAÇÃO - ACUSAÇÕES IMPROCEDENTES - SÓ UM INCORRIGÍVEL RECLAMA - O "REFORMATÓRIO BAIANO" É UMA GRANDE FAMÍLIA - ONDE DEVIAM ESTAR OS "CAPITÃES DE AREIA". ("Título da reportagem publicada na segunda edição da terça-feira do 'Jornal da Tarde', ocupando toda a primeira página, sobre o Reformatório Baiano, com diversos clichês do prédio e um do Diretor").

As cartas já apresentam o embate de duas vozes: uma denunciando os meninos de rua, incriminando-os e tratando-os como escórias da sociedade, tal como na reportagem de abertura do romance; e outra denunciando os poderes públicos, mais especificamente, o reformatório pelo tratamento dado aos meninos, como se vê na carta da mãe de um menor pobre e na de um padre, que toma a defesa das crianças:

Carta da mãe

/.../ é para falar do tal do reformatório que eu escrevo estas mal traçadas linhas. Eu queria que seu jornal mandasse uma pessoa ver o tal do reformatório para ver como são tratados os filhos dos pobres que têm a desgraça de cair nas mãos daqueles guardas sem alma. Meu filho Alonso teve lá seis meses e se eu não arranjasse tirar ele daquele inferno em vida, não sei se o desgraçado viveria mais seis meses. O menos que acontece pros filhos da gente é apanhar duas ou três vezes por dia. $O$ diretor de lá vive caindo de bêbedo e gosta de ver o cbicote cantar nas costas dos filhos dos pobres ./... (Maria Ricardina, costureira).

Carta do Padre José Pedro

/../ sou obrigado a sair da obscuridade em que vivo para vir vos dizer que infelizmente Maria Ricardina tem razão. As crianças no aludido reformatório são tratadas como feras, 
essa é a verdade. /.../ fazem-nas mais revoltadas ainda com espancamentos seguidos e castigos físicos verdadeiramente desumanos. /.../

Servo em Cristo

Padre José Pedro.

Essas vozes representam dois grupos sociais, "o pólo do alto e o pólo do baixo"7 : as elites, detentoras do poder e do discurso oficial, que demandam "a extinção do bando de criminosos", a prisão deles em reformatórios e que atribuem a situação dos meninos "ao desprezo dado à sua educação por pais pouco servidos de sentimentos cristãos"; os desprovidos de poder econômico, que fazem a crítica a essas elites, responsáveis pelos poderes públicos.

Nesse início do romance, vemos a interação autor-ouvinte-herói ${ }^{8}$ e a posição assumida pelo autor-criador por meio da seleção das palavras, ou melhor, "pelos julgamentos de valor associados com as palavras /.../ do ponto de vista dos próprios portadores desses julgamentos". (Bakhtin/Voloshinov, s/d). A posição do autor em relação a essas vozes, imagens do discurso de outrem "de linguagens, típicas e características" (Bakhtin, 1993:368) vai desenhando-se por meio dos gêneros acima citados e de outros indícios ao longo da narrativa, como se pode ver a seguir:

É aqui também que mora o chefe dos Capitães da Areia: Pedro Bala. /.../. Nunca soube de sua mãe, seu pai morrera de balaģo. Ele ficou sozinho e empregou anos em conhecer a cidade. (p. 26)

Vestidos de farrapos, sujos, semi-esfomeados, agressivos, soltando palavrões e fumando pontas de cigarro, eram, em verdade, os donos da cidade, os que a conheciam totalmente, os que totalmente a amavam, os seus poetas. (p.27)

Dormia (Pirulito) invariavelmente ali, onde as paredes do trapiche faziam um ângulo. Tinha disposto carinhosamente as suas coisas: um cobertor velho, um travesseiro que trouxera certa vez de um hotel onde penetrara levando as malas de um viajante, /.../ (p. 32)

7. Termos utilizados por Bezerra (2006)

8. Essas 3 instâncias são constitutivas do romance: o autor-criador,que não corresponde ao autorpessoa, mas a uma posição estético- formal, responsável pela criação e unidade da obra; o ouvinte, aquele que o autor leva em conta (não o público leitor concreto); e o herói, o objeto do enunciado, em relação ao qual o autor não é neutro (Bakhtin/Voloshinov, s/d). 
Por meio da voz do narrador, introduzida após a seção Cartas à redação, vemos a interação autor-herói e a posição de solidariedade, compaixão, ternura com os meninos de rua.

O discurso atributivo9 (Prince, 1978) e as falas dos representantes do poder opressor, expostas para o julgamento do leitor, também revelam a contraposição dialógica de pontos de vista:

Quando o levaram para aquela sala, Pedro Bala calculava o que o esperava. Não veio nenhum guarda. Vieram dois soldados de polícia, um investigador, o diretor do reformatório. Fecharam a sala. $O$ investigador disse numa voz risonha:

- Agora os jornalistas já foram, moleque. Tu agora vai dizer o que sabe, queira ou não queira.

$O$ diretor do Reformatório riu:

- Ora, se diz...

O investigador perguntou:

Onde é que vocês dormem?

Pedro Bala o olhou com ódio:

- Se tá pensando que eu vou dizer...

- Se vai...

- Pode esperar deitado.

Virou as costas. O investigador fez um sinal para os soldados. Pedro Bala sentiu duas chicotadas de uma vez. E o pé do investigador na sua cara. Rolou no chão, xingando.

- Ainda não vai dizer? - perguntou o diretor do Reformatório. - Isso é só o começo.

- Não - foi tudo o que Pedro Bala disse.

Agora davam-lhe de todos os lados. Chibatadas, socos e pontapés. O diretor do reformatório levantou-se, sentou-lhe o pé, Pedro caiu do outro lado da sala. Nem se levantou. Os soldados vibraram os chicotes./.../ Não falaria, fugiria do Reformatório, libertaria Dora. E se vingaria...Se vingaria... (p. 171-172)

$|\ldots|$

Esse capítulo narra a prisão de Pedro Bala, chefe dos Capitães da areia, por meio de outra notícia de jornal, e sua passagem pelo Reformatório. O

9. O discurso atributivo é o discurso do narrador que caracteriza as personagens, revela a sua expressão no contexto narrativo, antes de introduzir a fala reportada. 
narrador introduz as falas do investigador e do Diretor do Reformatório, no início da cena de tortura, com o verbo dizer, aparentemente neutro, mas acrescenta a descrição do modo de dizer ("com voz risonha", "riu"), que configura uma posição, a qual o narrador repudia.

Quando começa a tortura ("Agora davam-lhe de todos os lados"), o narrador intervém, descrevendo os golpes, perscrutando o discurso interior de Pedro Bala. O parágrafo termina com a raiva vingadora de Pedro Bala, em discurso indireto livre ("Não falaria, fugiria do Reformatório, libertaria Dora. E se vingaria... Se vingaria"): a voz é do narrador, do ponto de vista da composição do período, mas ouve-se a voz da personagem, com o qual o autor solidariza-se e refrange suas intenções.

Na seqüência abaixo, o discurso narrativo é entremeado pelo discurso interior de Pedro Bala:

O bedel Ranulfo, que o tinha ido buscar na polícia, levou-o à presença do diretor. Pedro Bala sentia o corpo todo doer das pancadas do dia anterior. Mas ia satisfeito, porque nada tinha dito, porque não revelara o lugar onde os Capitães da Areia viviam. /.../ Pela liberdade - pensava Pedro - dos seus amigos, ele apanhara uma surra na polícia. Agora seu corpo estava mole e dolorido, seus ouvidos cheios da moda que os presos cantavam. Lá fora, dizia a velha canção, é o sol, a liberdade e a vida. Pela janela Pedro Bala vê o sol. A estrada passa diante do grande portão do Reformatório. Aqui dentro é como se fosse uma eterna escuridão. Lá fora é a liberdade e a vida. "E a vingança", pensa Pedro Bala.

$\mathrm{O}$ diretor entra. O bedel Ranulfo o cumprimenta e mostra Bala. O diretor sorri, esfrega as mãos uma na outra, senta ante uma alta secretária. Olha Pedro Bala uns minutos:

- Afinal...Faz bastante tempo que espero este pássaro, Ranulfo.

O bedel sorri, aprovando as palavras do diretor.

- É o chefe dos tais Capitães da Areia. Veja... O tipo do criminoso nato. É verdade que você não leu Lombroso... Mas se lesse, conheceria. Traz todos os estigmas do crime na face. Com esta idade já tem uma cicatriz. Espie os olhos. Não pode ser tratado como um qualquer. Vamos lhe dar honras especiais... (p.173)

Aqui, a interação narrador-personagens ocorre por meio de diferentes esquemas de transmissão: a variante impressionista, usada para revelar o discurso interior da personagem Pedro Bala, e o discurso direto, para o discurso do diretor. A caracterização do diretor ("O diretor sorri, esfrega as 
mãos uma na outra") e do bedel ("O bedel sorri, aprovando as palavras do diretor") pelo narrador denuncia as posições das duas personagens diante das práticas desumanas executadas pelos poderes constituídos e aprovadas pela mídia e pela opinião comum.

\section{Considerações finais}

Iniciamos esse artigo com um anúncio dos limites dessa proposta, uma vez que se trata de um trabalho de lingüista cujo foco é a interação. A análise de alguns fragmentos ilustra contudo a tese de que a interação entre os discursos no romance representa posições axiológicas de sujeitos, pontos de vista sobre o objeto do discurso elaborados por um esteta. Em Capitães da Areia, os diferentes tipos de interação representam artisticamente pelo menos dois grupos sociais e dois posicionamentos discursivos: o do narrador em sintonia com o autor, que revela solidariedade com os menores de rua, frutos de uma sociedade extremamente desigual, injusta e cruel, denunciando ao mesmo tempo as elites; o dos excluídos, com o qual um segmento da igreja está em sintonia. Esses confrontos são introduzidos pelos discursos: do narrador, das personagens e dos gêneros intercalados, mostrando assim a relevância da interação discursiva, não só como modo de dizer o outro e de desvelar as relações sócio-verbais representadas no romance, mas também como lugar de reconciliação entre lingüistas e literatos.

Recebido em janeiro de 2007

Aprovado em agosto de 2007 E-mail: dorisarruda@terra.com.br

\section{REFERÊNCIAS Bibliográficas}

Amado, Jorge. 1991. Capitães da areia. $74^{\mathrm{a}}$ edição. Rio de Janeiro: Editora Record.

Bakhtin, Mikhaill. 2003. Estética da criação verbal. São Paulo: Martins Fontes. . 1997. Problemas da Poética de Dostoievski. $2^{\text {a }}$ edição, Rio de Janeiro: Forense Universitária (1 $1^{a}$ edição, 1929/1963).

. 1993. Questões de Estética e de Literatura. $3^{\text {a }}$ edição. São Paulo: UNESP/ Hucitec. 
Bakhtin, Mikhaïl \& Voloshinov, Valentin Nicolaévitch. 1995. Marxismo e Filosofia da Linguagem. $7^{\text {a }}$ ed. São Paulo: Ed. Hucitec ( $1^{\text {a }}$ edição, 1929). . S/d. O Discurso na Vida e o Discurso na Arte. Tradução para o português, feita por Carlos Alberto Faraco e Cristovão Tezza, tendo como base a tradução inglesa de I. R. Titunik (Discourse in life and discourse in art - concerning sociological poetics), publicada em Valentin Nicolaévitch Voloshinov, Freudism, New York: Academic Press, 1976. (1 $1^{a}$ edição, 1926)

Bezerra, Paulo. 2006. Dialogismo e polifonia em Esaú e Jacó. In: Carlos Alberto Faraco, Cristovão Tezza \& Gilberto Castro. Org. Vinte ensaios sobre Mikhail Bakhtin. Petrópolis: Ed. Vozes.

BraIt, Beth. (org.). 2005. Bakhtin - conceitos-chave. São Paulo: Contexto. . 2006. Bakhtin - outros conceitos-chave. São Paulo: Contexto.

CunHa, Dóris de Arruda Carneiro da. 1992. Discours rapporté et circulation de la parole, Leuven/Louvain-la-Neuve: Peeters/Louvain-la-Neuve.

- 1995. Modalidades de transmissão do discurso no face a face interacional. In: Anais do IX Encontro Nacional da ANPOLL, João Pessoa: UFPB Editora, v. 2: 1149-1158.

. 1997. O discurso direto como fator de textualidade na fala. In: Ingedore Villaça Koch; Kazue Saito Monteiro de Barros. Org. Tópicos em Lingüística de Texto e Análise da Conversação. Natal: EDUFRN: 47-52. . 1998. "Vozes e gêneros discursivos na fala e na escrita". Investigaçôes - Lingüística e Teoria Literária 8: 129-145.

. 2002. O funcionamento dialógico em revistas e artigos de opinião. In: Angela Dionisio, Ana Raquel Machado \& Maria Auxiliadora Bezerra. Org. Gêneros textuais E Ensino. Rio de Janeiro: Lucerna. . 2003. A pluridiscursividade em Contos de Rubem Fonseca. In: Luiz Antônio Marcuschi \& Judith Hoffnagel. Ed. Anais do I Congresso e IV Colóquio da Associação Latinoamericana de Análise do Discurso. Recife. ( CD -ROM).

. 2004. L'interaction discursive dans la fiction brésilienne. In: Sophie Marnette, Laurence Rosier \& Juan Manuel Lopez Muñoz. Org. Le Discours Rapporté Dans Tous Ses Etats: question de frontières. Paris: L'Harmattan.

. 2004. L'interaction discursive dans la fiction brésilienne. In: Sophie Marnette, Laurence Rosier \& Juan Manuel Lopez Muñoz. Org. Le Discours Rapporté Dans Tous Ses Etats: question de frontières. Paris: L'Harmattan. 
. 2005 Circulation de la parole et genres discursifs dans la fiction et dans la presse. In: Juan Manuel Lopez Muñoz, Sophie Marnette \& Laurence Rosier. Org. Dans la jungle des discours. Genres et discours rapporté. Cádiz: Servicio de Publicaciones de la Universidad de Cádiz.

Cunha, Dóris de Arruda Carneiro da \& Valors, Michelle Jácome. 2003. La mise en paragraphes du discours rapporté dans les récits de fiction brésiliens. Modèles Lingüistiques 48, tome. XXIV, fasc. 2 .

Cunha, Dóris de Arruda Carneiro da \& Oliveira Jr. Miguel. 2004. Prosody As Marker of Direct Reported Speech Boundary. Proceedings of the 2nd International Conference on Speech Prosody. 263-266.

Cunha, Dóris de Arruda Carneiro da \& Arabyan, Marc. 2004. La ponctuation du discours direct - des origines à nos jours. L'Information Grammaticale, 105: 35-45.

Faraco, Carlos Alberto. 2005a "Interação e linguagem: balanço e perspectivas" Texto apresentado como conferência de encerramento do Congresso Internacional Linguagem e Interação, realizado na UNISINOS (São Leopoldo - RS), de 22 a 25 de agosto de 2005.

. 2005b. Autor e autoria. In: Beth BraIt. Org. Bakbtin: conceitoschave. São Paulo: Contexto.

Faraco, Carlos Alberto. 2003 Linguagem e Diálogo - As Idéias Lingüísticas do Círculo de Bakbtin. Curitiba: Criar Edições.

Françors, Frédéric. 2006. Dialogisme des «voix » et hétérogénéité constitutive du «sens». Le «textuel» et l' «extratextuel». Le quotidien et le « littéraire ». Le « contenu», la forme, et le ressenti. Communauté et différences d'accentuation chez Volochinov, Bakhtine et Vygotzki. Une contribution indirecte à la pédagogie du «texte littéraire ». (No prelo).

. 1998. Le discours et ses entours. Paris: L'Harmattan.

Maingueneau, Dominique. 2004 Le discours littéraire. Paratopie et scène d'énonciation, Paris: A. Colin.

. 2000. Linguistique et littérature: le tournant discursif. In: Prospettive della francesistica nel nuovo assetto della didattica universitaria, Gabriella Fabbricino éd., Società Unversitaria per gli Studi di Lingua et Letteratura Francese, Atti del Convegno Internazionale di NapoliPozzuoli, 2000: 25-38. Repris dans Sciences du langage, 2005-2006, Les Cahiers de l'ED 139, Publications de l'Université Paris X Nanterre, 2006: 133-146. http://perso.orange.fr/dominique.maingueneau/ index.html 
Prince, Gerard. (1978) Le discours attributif et le récit. Poétique, 35.

VAlors, Michelle Jácome. (2003) “Entre o visível e o 'lisível' em Capitães da Areia - o dialogismo vislumbrado na materialidade do texto". Ao Pé da Letra 5 vol.1: 69-78. 